\title{
ANÁLISE ESTRATÉGICA DO CROWDFUNDING E SUA RELAÇÃO COM O MERCADO DE CAPITAIS BRASILEIRO
}

\author{
Bruno Alves Apolinário ${ }^{1}$ \\ Frederico de Andrade Gabrich ${ }^{2}$
}

\section{RESUMO:}

O grande desafio para as startups - empresa cujo modelo de negócio é pautado na incerteza e que buscam desenvolver produtos/serviços inovadores - é a obtenção de financiamento para o exercício de sua atividade negocial. O crowdfunding tem sido a ferramenta mais utilizada para essa finalidade. Não obstante a eficiência que esse instrumento possa propiciar, a falta de regulamentação, conjugada com a ausência de segurança jurídica daí decorrentes, tem impedido o acesso das startups ao Mercado de Capitais brasileiro. Objetiva este estudo, a partir da Análise Estratégica do Direito, demonstrar a possibilidade de conjugar esses dois instrumentos.

PALAVRAS-CHAVE: Mercado de Capitais; Valores Mobiliários; Crowdfunding; Análise Estratégica do Direito.

\section{STRATEGIC ANALYSIS OF CROWDFUNDING AND ITS RELATIONSHIP WITH THE BRAZILIAN CAPITAL MARKET}

\begin{abstract}
The great challenge for startups - a company whose business model is based on uncertainty and that seek to develop innovative products / services - is to obtain financing for the exercise of its business activity. Crowdfunding has been the most widely used tool for this purpose. Despite the efficiency that this instrument can provide, the absence of regulation, coupled with the absence of legal security resulting therefrom, has prevented startups from accessing the Brazilian Capital Market. The objective of this study, based on the Strategic Analysis of Law, is to demonstrate the possibility of combining these two instruments.
\end{abstract}

KEYWORDS: Capital Market; Securities; Crowfundig; Strategic Analiysis of Law.

\section{INTRODUÇÃ̃ ${ }^{3}$}

O Direito começa no fato jurídico, que é qualquer fato que cria, extingue ou modifica direitos e obrigações de alguma pessoa. Por isso os fatos jurídicos não podem ser

\footnotetext{
${ }^{1}$ Mestrando em Direito pela Universidade FUMEC. Especialista em Direito Empresarial pela Universidade FUMEC. Professor da Faculdade da Saúde e Ecologia Humana - FASEH. Mestrando em Direito pela Universidade FUMEC.

${ }^{2}$ Doutor, Mestre e Especialista em Direito Empresarial/Comercial pela UFMG. Professor da Universidade FUMEC. Coordenador do projeto de pesquisa Design Instrucional e Inovação das Metodologias de Ensino Jurídico (FAPEMIG).

${ }^{3}$ Os autores agradecem o apoio recebido da Fundação de Amparo à Pesquisa do Estado de Minas Gerais FAPEMIG e da Universidade Fumec, para realização da pesquisa e divulgação dos seus resultados.
} 
desconsiderados no ensino e na interpretação do direito. E isso é mais importante ainda em relação às empresas, ao mercado e ao direito empresarial.

Assim, na prática empresarial e de mercado, o maior desafio e problema que se apresenta àqueles que resolvem iniciar qualquer empreendimento, consiste, sem dúvida, na capitação de recursos para o financiamento e para o exercício da atividade empresarial, principalmente quando se trabalha com a incerteza de um modelo de negócios ainda em elaboração, como ocorre com as empresas iniciantes, que se dedicam à inovação, as chamadas empresas startups. E este é o problema prático e também jurídico que esta pesquisa procura enfrentar, por meio do referencial teórico da Análise Estratégica do Direito, proposto por Frederico Gabrich, segundo o qual o direito deve ser usado para a estruturação dos objetivos das pessoas (no caso específico dessa pesquisa, das empresas startups e dos seus sócios), para que eles aconteçam com a maior eficiência possível, preferencialmente sem a existência de conflitos e sem que eventuais conflitos sejam dirimidos por meio de processo judicial.

Neste cenário, impõe-se a necessidade de encontrar saídas jurídicas que possibilitem a capitalização desses empreendimentos iniciantes, no intuito de garantir-lhes os recursos financeiros necessários para o desenvolvimento de suas respectivas atividades empresariais.

As operações de crowdfunding, termo que pode ser traduzido como "financiamento pela multidão" - ou mais tecnicamente, financiamento coletivo -, tem se demonstrado instrumento eficiente para angariar os fundos necessários para o desenvolvimento de projetos inovadores, possibilitando que o consumo e o investimento sejam dirigidos para aqueles empreendimentos que satisfaçam, realmente, os problemas, desejos, vontades e/ou necessidades humanas.

No entanto, a ausência ou a deficiência da regulação normativa acerca desta operação tem trazido relativa insegurança jurídica para quem a utiliza, o que acaba prejudicando a sua propagação e o acesso a investimentos de maior monta, disponíveis no Mercado de Capitais.

Por isso, com uso da metodologia dedutiva, o presente trabalho visa analisar a operação de crowdfunding à luz da Análise Estratégica do Direito, no intuito de demonstrar a desnecessidade de elaboração de complexa regulamentação sobre tema, valendo-se dos institutos já existentes no ordenamento jurídico brasileiro, especificamente no que tange ao valor mobiliário denominado contrato de investimento coletivo, cujas regras poderiam balizar a operação em estudo. 
No intuito de guiar o leitor e apresentar o trabalho, expõe-se a dinâmica proposta para este: no item 2, será delineado o marco teórico deste estudo, a Análise Estratégica do Direito, apresentando os seus principais postulados, ainda que de maneira concisa, para pautar o raciocínio utilizado. A seguir, serão tecidas considerações sobre o crowdfunding, tais como: sua origem histórica, definição etimológica, dinâmica da operação e sua aplicação. No item 4, será analisada a relação entre a operação em estudo e a atuação da Comissão de Valores Mobiliários - CVM, no que concerne a este assunto, direcionando-se, principalmente, para a possibilidade de caracterização do crowdfunding como um contrato de investimento coletivo. Por fim, serão expostas as conclusões obtidas ao longo deste trabalho.

\section{A ANÁLISE ESTRATÉGICA DO DIREITO}

Constata-se, principalmente a partir do início do século XXI, que a realidade social se alterou profundamente. O resultado proveniente da soma da eficiência da comunicação e a rapidez da informação, fatos típicos deste novo milênio, associado aos efeitos da grande revolução tecnológica e social, ocorrida inicialmente nos anos 1990 do século passado, alteraram (e ainda alteram) por completo a dinâmica da sociedade em que vivemos.

O Direito, entretanto, tenta resistir bravamente a essas modificações e evoluções sociais, conservando o seu modo próprio e ultrapassado de pensar a realidade, causando descompasso entre as necessidades da sociedade e as respostas dada pelo conhecimento jurídico às demandas que lhe são submetidas. E esse descompasso é observado tanto no ensino, quanto na prática jurídica e judicial. O modelo mental que ainda predomina na ciência do Direito pressupõe a existência de um conflito para que o Estado, por meio do Poder Judiciário e das leis, atue de maneira a determinar a solução deste pressuposto conflito e a almejada "paz social". Ocorre, todavia, que, nos tempos atuais, parte cada vez mais significativa das pessoas (naturais e jurídicas) têm como objetivo o "bem viver", a qualidade de vida, a colaboração, a sustentabilidade psicológica, social e ambiental, preferencialmente sem conflitos e sem processos judiciais.

Nesse contexto, faz-se necessária a evolução do modelo mental, da forma de ensino e de aplicação do Direito, para adequá-lo aos desejos, vontades e necessidades das pessoas desse nosso tempo, para que ele possa contribuir, efetivamente, para sustentação e para a evolução da sociedade. Uma das alternativas teóricas possíveis para essa evolução do 
modelo mental do Direito e sua adequação à contemporaneidade é a Análise Estratégica do Direito.

Estruturada em consonância com as balizas da escola do planejamento estratégico, a Análise Estratégica do Direito implica a utilização de um pensamento jurídico estratégico, segundo o qual:

\begin{abstract}
Esse pensar estratégico pressupõe uma disposição de encarar o conhecimento científico com que se conta e as pessoas envolvidas na execução de uma atividade organizada (no Estado ou fora dele), como instrumentos necessários ao alcance dos objetivos pré-estabelecidos. Tais objetivos normalmente estão vinculados à determinação da maior felicidade possível, do maior número possível de pessoas, com o menor custo (de tempo e de dinheiro) possível, diante das circunstâncias fáticas, jurídicas, econômicas, sociais e políticas relacionadas ao caso.

No plano jurídico, o pensar estratégico exige uma mudança radical na maneira de conceber o Direito, tanto pelos próprios juristas, quanto e, principalmente, pelas pessoas responsáveis pela gestão do Estado e das empresas privadas (GABRICH, 2010, p. 16).
\end{abstract}

De acordo com essa visão do Direito, o planejamento e a construção de possíveis cenários, ante os objetivos das pessoas e as condições fáticas apresentadas, são medidas que se impõem, pois assim poderá o jurista - estrategista jurídico - entender de maneira completa, as particularidades de cada caso concreto, assim como as consequências de cada uma das opções possíveis, o que possibilitaria a escolha da estratégia jurídica que melhor se apresentasse para a mais eficiente estruturação dos objetivos das pessoas, preferencialmente sem conflitos e, caso esses venham porventura a existir, solucionados preferencialmente sem o processo judicial (mediante a autocomposição, a conciliação, a mediação ou a arbitragem).

Nessa ótica, a Análise Estratégica do Direito propõe que o ordenamento jurídico deve ser visto como uma extensa gama de possíveis soluções para os problemas reais e que, para se escolher a estratégia que melhor se adeque ao caso concreto, faz-se necessária a realização de um briefing (para que o estrategista possa reconhecer os objetivos reais das pessoas) e a valorização da atividade interpretativa da norma jurídica estabelecida pelas diversas fontes do direito - e não apenas da lei formal -, assim como o reconhecimento que a função precípua do Direito não pode ser única e exclusivamente a pacificação social, mas sim, primeiro, a estruturação dos objetivos das pessoas (físicas ou jurídicas), com o menor custo possível (psicológico, de tempo, social, ambiental, econômico, financeiro), a fím de garantir a maior felicidade possível (o maior bem estar possível), para o maior número possível de pessoas em cada caso concreto.

Nesse sentido, segundo GABRICH: 
[...] o pensar estratégico requer, no plano jurídico, a necessidade de encarar o Direito como um conjunto de alternativas colocadas à disposição do jurista para a estruturação de empresas, negócios e pessoas (físicas e jurídicas, de direito público e de direito privado), de maneira a permitir que os objetivos traçados sejam alcançados com o menor custo possível, como, inclusive, é proposto pela escola da análise econômica do Direito. Nesse aspecto, inclusive, cumpre destacar que a análise estratégica do Direito utiliza vários elementos propostos pela análise econômica do Direito, mas com ela não se confunde. A análise estratégica do Direito vê no sistema normativo um conjunto de alternativas colocadas à disposição para a realização dos objetivos propostos pela pessoa, empresa, Estado ou qualquer tipo de organização pública ou privada. E essas alternativas devem ser avaliadas sob vários aspectos e cenários, antes da decisão de implementação, dentre os quais se destacam as análises políticas, culturais, sociais e, logicamente, também de custos e benefícios econômicos (GABRICH, 2010, p. 16).

Dessa maneira, entender o Direito estrategicamente implica a alteração da hermenêutica jurídica tradicional, para que seja valorizada a interpretação de todas as nuances dos casos concretos estudados, bem como a compreensão de que a norma jurídica que será aplicável a cada situação somente decorre do processo interpretativo de todas as fontes do Direito conjugadas, sendo que essas não se restringem apenas à lei formal, mas abarcam a jurisprudência, a doutrina, o costume, os contratos (públicos e privados), os atos administrativo normativos, dentre outras fontes formais e informais do Direito.

Saliente-se, também, que a interpretação dada não poderá ser desconexa do objetivo concretamente identificado por meio do briefing ou do problema fático enfrentado. Assim, a Análise Estratégica do Direito atrela a utilização do ordenamento jurídico à estruturação de questões reais das pessoas, vinculando-se a atividade hermenêutica à utilidade da resposta dada, viabilizando-se a adequação da estratégia jurídica traçada ao dinamismo da realidade.

Assim, conforme GABRICH expõe:

De acordo com essa nova concepção da interpretação e aplicação das normas jurídicas, estas existem para solucionar ou prevenir conflitos da vida real. Por isso a interpretação deve ser útil e pragmática.

Por outro lado, não há como negar que a vida contemporânea é marcada pelo pluralismo de ideias e pelo dinamismo frenético das situações fáticas.

Não obstante, convém observar que os textos das normas são estáticos e muitas vezes não acompanham o dinamismo intenso da vida contemporânea. $\mathrm{O}$ texto da norma é estabelecido de acordo com as finalidades econômicas e sociais que justificaram a sua promulgação, em decorrência de um acordo de vontades decorrente da vontade geral (GABRICH, 2010, p. 17).

Em suma, a Análise Estratégica do Direito pressupõe o reconhecimento do papel do Direito como estruturador de objetivos das pessoas, buscando traçar, dentre as possíveis 
soluções existente no ordenamento jurídico, aquela estratégia jurídica que melhor se adeque às necessidades do caso real, possibilitando a redução de custos de modo geral e especificamente os custos decorrentes dos conflitos e dos processos judiciais.

Essa visão do Direito implica o reconhecimento da multiplicidade das fontes jurídicas, assim como da importância do planejamento e da construção de cenários possíveis, a fim de se verificar as consequências decorrentes da estratégica adotada e seus reflexos, o que implica a compreensão da dinâmica vital do próprio Direito.

No processo de construção de estratégias jurídicas, a realização de um briefing e/ou de uma auditória jurídica pode ser definida como o primeiro passo e o mais importante deles, pois possibilita o conhecimento de toda a complexidade da questão em estudo, através da compreensão das particularidades internas e externas envolvidas em cada caso, de maneira integral e profunda, o que concede ao estrategista jurídico todas as informações necessárias para traçar a estratégias que se demonstrem como as mais adequadas em cada caso.

Acerca do papel exercido pela auditória jurídica e a sua importância para aplicação da Análise Estratégica do Direito, ensina GABRICH:

\footnotetext{
Basicamente, a auditoria jurídica consiste na análise e no diagnóstico das empresas, negócios e pessoas, dos fatos e dos atos jurídicos, e da adequação dessas pessoas, fatos e atos às normas existentes, válidas e eficazes no ordenamento jurídico, considerando a interpretação corrente na doutrina, na vida negocial e na jurisprudência. A auditoria jurídica constitui, portanto, etapa fundamental no processo de conhecimento da empresa, negócio ou pessoa (física ou jurídica, de direito público ou de direito privado) que será objeto de uma análise estratégica do Direito (GABRICH, 2010, p. 23).
}

Verifica-se, portanto, que a auditoria jurídica é ponto crucial, e inicial, para a devida compreensão das nuances de cada caso, pois viabiliza o entendimento interno dos pontos fortes e fracos das pessoas - físicas e/ou jurídicas - da quais se pretende estruturar estrategicamente os objetivos.

Nessa ótica, dentro da dinâmica deste trabalho, faz-se necessário reafirmar um dos principais objetivos teóricos das empresas startups, que consiste na necessidade de financiamento externo de suas atividades empresariais, bem como a compreensão introspectiva do crowdfunding, o que será realizado a seguir.

\section{A DINÂMICA DO CROWDFUNDING}


A palavra crowdfunding tem sua origem etimológica na língua inglesa, sendo a junção de dois termos, a saber, crowd - que significa "multidão" - e funding - que pode ser traduzido como financiamento (COCATE, PERNISA JÚNIOR, 2012). A partir disso, pode-se compreender o crowdfunding como meio de financiamento de um projeto determinado, realizado por intermédio de quantidade indeterminada de sujeitos ou, como sugere o próprio termo, verdadeiramente uma "multidão".

A ideia de angariar fundos para determinado projeto, utilizando de investimento da coletividade, pode ser considerada como instrumento próprio do século XXI, sendo o seu maior exemplo a arrecadação de fundos para campanhas políticas e partidárias, via rede mundial de computadores - a Internet. Essa prática se iniciou nos anos 2000, mas apenas em 2008, durante a campanha de Barack Obama para a presidência dos Estados Unidos da América - EUA -, que esse instrumento se fortaleceu, em virtude do referido candidato ter conseguido levantar aproximadamente US\$ 272 milhões, com a contribuição espontânea e voluntária de mais de dois milhões de pequenos doadores (COCATE, PERNISA JÚNIOR, 2012).

Em decorrência disso, a ideia da utilização desse tipo de financiamento se difundiu no meio artístico, cujas obras - filmes, peças de teatro, $C D$ 's, a título de exemplo possuem elevados custos de produção, o que dificulta a sua realização por aqueles que não se encontram consolidados no mercado. Em razão dessa particularidade, ainda nos anos 2000, houve a proliferação de sites que se propunham a realizar essa operação de capitação de fundos oriundos do público, da coletividade, como o europeu Sellaband e, em 2009, o norteamericano Kickstarter - que pode ser considerado a maior plataforma on line para financiamento de manifestações artísticas de qualquer natureza -, no intuito de financiar aqueles empreendimentos culturais e artísticos (COCATE, PERNISA JÚNIOR, 2012).

No Brasil, iniciativas como o pioneiro site Vakinha, em 2009, foram utilizadas para propagar e beneficiar diversas atividades de cunho cultural, e/ou até atividades de cunho pessoal, tais como a compra de equipamentos médicos, carros, cadeiras de rodas etc (COCATE, PERNISA JÚNIOR, 2012). O site Catarse, no entanto, foi a primeira plataforma eletrônica voltada exclusivamente para promoção de atividades culturais, utilizando-se do financiamento coletivo (COCATE, PERNISA JÚNIOR, 2012).

Não obstante, o crowdfunding é inspirado em um conceito mais amplo, o crowdsourcing, que surgiu em junho de 2006, em decorrência de artigo publicado pelo jornalista estadunidense Jeff Howe, na revista Wired, na qual o autor demonstrou as 
perspectivas da nova mídia que estava surgindo e que possibilitava a produção/criação de conteúdo, com a colaboração de número indeterminado de agentes amadores, assim como seus possíveis impactos na cultura e nos meios de comunicação globais (COCATE, PERNISA JÚNIOR, 2012). Apenas partir dessa ideia que se demonstrou possível a criação colaborativa de produtos como a Wikipédia, dos sistemas operacionais livres de código aberto - também chamados de open source - como o Linux e o Apache, dos bancos de dados The Internet Movie Database (IMDb) e o IStockphoto, banco de imagens na internet (VALIATI, 2013).

Percebe-se, portanto, que a ideia de financiamento coletivo - crowdfunding -, assim como o conceito de crowdsourcing, propiciam a colaboração dos agentes - seja de modo direto ou indireto -, permitindo a comunhão de esforços, para alcance de determinado fim. Essa operação se demonstra, portanto, como uma estratégia interessante para os novos negócios em desenvolvimento - as chamadas startups - cujo único elemento palpável é a incerteza $^{4}$, pois possibilita a realização dos objetivos empresariais e a redução dos custos envolvidos nos projetos.

A dinâmica do processo de crowdfunding demonstra-se extremamente simples e pode ser descrita da seguinte maneira: (i) primeiramente o idealizador - aquele que teve a ideia do produto/serviço que visa satisfazer a um problema, desejo, vontade ou necessidade humana - deve cadastrar o seu projeto em uma das plataformas on line destinadas a esse tipo de financiamento ${ }^{5}$. Nesse momento, o interessado na captação (idealizador) deve realizar a exposição de seu projeto - por meio de vídeos, podcasts, apresentações interativas, videoconferência ou qualquer outro meio -, bem como determinar o valor necessário para a realização dos seus objetivos, assim como o prazo para contribuição e para a possível retribuição que será destinada ao doador; (ii) em seguida, o interessado deve proceder à divulgação da operação, pelos meios que considerar cabíveis; (iii) o doador, após ser alcançado pela divulgação, deverá acessar a plataforma escolhida e, se houver interesse pelo projeto, realizar a doação; (iv) caso seja alcançado dentro do prazo estipulado pelo idealizador o valor pretendido, poderá ele retirá-lo e realizar o seu projeto, remunerando a plataforma com porcentagem que varia entre $5 \%$ (cinco por cento) a 7,5\% (sete e meio por cento) do valor total do financiamento. Caso não seja alcançado o valor necessário, os valores doados

\footnotetext{
${ }^{4}$ Sobre o tema, vide RIES, Eric. A startup enxuta: como os empreendedores atuais utilizam a inovação contínua para empresas extremamente bem sucedidas. São Paulo: Lua de Papel, 2012.

5 Conforme demonstrado COCATE, PERNISA JÚNIOR(2012), somente no Brasil há mais de 20 (vinte) plataformas direcionadas à realização de operações de crowdfunding.
} 
deverão ser restituídos aos doadores pela plataforma escolhida, sem que seja disponibilizada qualquer quantia para o idealizador, assim como para remunerar a plataforma utilizada (COCATE, PERNISA JÚNIOR, 2012).

Dessa maneira, constata-se que os principais recursos que possibilitarão o sucesso ou não do empreendimento são: a divulgação da operação de financiamento coletivo feita pelo idealizador, assim como a devida apresentação do seu produto/serviço, de forma clara, objetiva e atraente, a fim de cativar os possíveis doadores. Note-se que a clareza e a precisão das informações prestadas pelo idealizador, são pressupostos fundamentais para o sucesso da operação.

Importante destacar que a retribuição que será dada ao doador, em razão de sua contribuição para a operação de crowdfunding, usualmente é realizada dentre uma das seguintes possibilidades: (a) a entrega de brinde, recompensa, que consiste em dar ao doador presente - seja um chaveiro, camiseta, ingresso para shows, exemplar de livro e/ou mídia digital - correspondente à sua contribuição financeira destinada para a realização do projeto; (b) a aquisição do produto resultante do projeto financiado, nesse caso, o valor da contribuição dada pelo doador deverá ser menor do que o possível valor de mercado do bem,

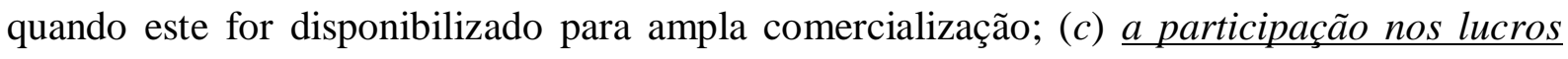
pelo idealizador, apurado após a comercialização futura do produto/bem/serviço financiado, com a possibilidade de o doador se tornar sócio do idealizador (COCATE, PERNISA JÚNIOR, 2012).

A operação de crowdfunding demonstra-se geralmente benéfica para todas as partes envolvidas, pois: permite o alinhamento de interesses das partes; possibilita ao idealizador realizar o seu projeto e exercer a atividade negocial pretendida; concede à plataforma a remuneração devida em decorrência de sua intermediação da operação; permite ao doador, geralmente consumidor, escolher qual produto/bem/serviço satisfaça ao seu problema, desejo, vontade e/ou necessidade, de maneira eficaz e inovadora, o que acaba possibilitando a alteração nos rumos do consumo; conecta a realidade dos consumidores à produção daqueles que empreendem.

Nessa ótica, a operação de financiamento coletivo se demonstra como importante instrumento para o avanço da sociedade e dos negócios, não obstante ainda seja incipiente, embora existam várias plataformas que a viabilizem no Brasil. No entanto, não há absoluta segurança jurídica quanto ao seu tratamento legal, pois a regulação desse tema inexiste ou ainda é inadequada. 


\section{A RELAÇÃO ENTRE O CROWDFUNDING, A CVM E O MERCADO DE CAPITAIS}

Conforme explicitado anteriormente, a operação de crowdfunding ocorre mediante a disponibilização ao público, pela Internet, da possibilidade para contribuir para o financiamento e a realização de determinado projeto.

Esse ato jurídico (ato voluntário que cria, extingue e/ou modifica direitos e obrigações) indiscutivelmente encontra-se relacionado entre o rol estabelecido pelo $\S 3^{\circ}$ do art. 19 da Lei n. ${ }^{\circ}$ 6.385/1976 (que dispõe sobre o mercado de valores mobiliários e cria a Comissão de Valores Mobiliários - CVM), segundo o qual:

\footnotetext{
Art . 19. Nenhuma emissão pública de valores mobiliários será distribuída no mercado sem prévio registro na Comissão.

[...]

$\S 3^{\circ}$ - Caracterizam a emissão pública:

I - a utilização de listas ou boletins de venda ou subscrição, folhetos, prospectos ou anúncios destinados ao público;

II - a procura de subscritores ou adquirentes para os títulos por meio de empregados, agentes ou corretores;

III - a negociação feita em loja, escritório ou estabelecimento aberto ao público, ou com a utilização dos serviços públicos de comunicação (BRASIL, 1976).
}

De acordo com o disposto no artigo $8^{\circ}$ da Lei n. 6.385/76, cabe à Comissão de Valores Mobiliários - CVM, a regulação específica e a fiscalização do mercado de valores mobiliários.

Por isso, em complementação aos ditames legais gerais, encontra-se a disposição específica, estabelecida pelo art. $3^{\circ}$ da Instrução Normativa da CVM n. ${ }^{\circ} 400$, de 29 de dezembro de 2003 - Instrução Normativa CVM n. ${ }^{\circ}$ 400/2003:

\footnotetext{
Art. $3^{\circ}$ São atos de distribuição pública a venda, promessa de venda, oferta à venda ou subscrição, assim como a aceitação de pedido de venda ou subscrição de valores mobiliários, de que conste qualquer um dos seguintes elementos:

I - a utilização de listas ou boletins de venda ou subscrição, folhetos, prospectos ou anúncios, destinados ao público, por qualquer meio ou forma;

II - a procura, no todo ou em parte, de subscritores ou adquirentes indeterminados para os valores mobiliários, mesmo que realizada através de comunicações padronizadas endereçadas a destinatários individualmente identificados, por meio de empregados, representantes, agentes ou quaisquer pessoas naturais ou jurídicas, integrantes ou não do sistema de distribuição de valores mobiliários, ou, ainda, se em desconformidade com o previsto nesta Instrução, a consulta sobre a viabilidade da oferta ou a coleta de intenções de investimento junto a subscritores ou adquirentes indeterminados;
} 
III - a negociação feita em loja, escritório ou estabelecimento aberto ao público destinada, no todo ou em parte, a subscritores ou adquirentes indeterminados; ou IV - a utilização de publicidade, oral ou escrita, cartas, anúncios, avisos, especialmente através de meios de comunicação de massa ou eletrônicos (páginas ou documentos na rede mundial ou outras redes abertas de computadores e correio eletrônico), entendendo-se como tal qualquer forma de comunicação dirigida ao público em geral com o fim de promover, diretamente ou através de terceiros que atuem por conta do ofertante ou da emissora, a subscrição ou alienação de valores mobiliários (CVM, 2003) .

Verifica-se, portanto, que a operação de crowdfunding se enquadra na definição de oferta pública, pois visa angariar recursos financeiros para o financiamento de projetos, mediante apelo direto ao público, o que possibilita que a coletividade indistinta de pessoas possa investir/doar esses recursos para a consecução de objetivos empresariais do proponente (idealizador do projeto).

Diante dessa constatação, a Comissão de Valores Mobiliários - CVM, por intermediação da sua Superintendência de Desenvolvimento do Mercado - SDM e atenta ao seu papel regulador do mercado de capitais, realizou audiência pública relativa à proposta de regulamentação SDM/CVM n. ${ }^{\circ}$ 06/2016, com prazo até dezembro de 2016, visando ampliar debate sobre Minuta de Instrução que dispõe sobre a oferta pública de distribuição de valores mobiliários de emissão de empreendedores de pequeno porte realizada com dispensa de registro na Comissão de Valores Mobiliários e por meio de plataformas eletrônicas de investimento participativo na rede mundial de computadores ("investment-based crowdfunding"), cujos principais e mais relevantes temas, foram assim definidos:

\begin{abstract}
Os principais elementos propostos para a regulamentação do investment-based crowdfunding, e que representam aprimoramentos em relação ao regime de dispensa já existente na Instrução CVM no ${ }^{\circ}$ 400, de 2003, dizem respeito a aspectos como: (a) a definição de critérios de elegibilidade dos emissores; (b) o aumento do limite de captação anual; (c) o estabelecimento de procedimentos a serem utilizados na condução da oferta; (d) a imposição de limites de investimento aos investidores de varejo; (e) a padronização das informações da oferta consideradas essenciais; (f) a obrigação de concessão de amplo e equitativo acesso às informações da oferta; (g) o estabelecimento de requisitos para o registro e autorização para o funcionamento das plataformas; (h) a introdução de regras de conduta e de vedação a determinadas atividades; (i) a vedação ao uso de material publicitário; (j) a introdução de informes periódicos das atividades das plataformas a serem enviados para a CVM; e (k) a permissão de cooferta por sindicatos de investimento participativo, que poderão, opcionalmente, contar com um investidor líder [...] .
\end{abstract}

À referida proposta foram apresentadas várias manifestações por diversos agentes do mercado, que lidam com a operação de crowdfunding, que opinaram contrariamente a alguns pontos da proposta, e demonstraram a relevância do tema aqui estudado, bem como a necessidade de sua discussão com maior cautela, pois caso seja realizada regulamentação 
equivocada e ineficiente sobre o tema, poderá existir prejuízo a todas as operações de financiamento coletivo em andamento no país, o que irá dificultar o cenário para as empresas startups em operação, assim como irá impossibilitar ou dificultar o surgimento de novos negócios inovadores, que precisam desse tipo de financiamento para sua organização.

Não obstante a relevância e urgência da regulamentação específica das operações de crowdfunding pela CVM, é fundamental ressalatar (com o devido respeito de possíveis opiniões contrárias), que já existe regramento no ordenamento jurídico brasileiro, que poderia embasar o financiamento coletivo. Trata-se do valor mobiliário denominado contrato de investimento coletivo.

Nesse sentido, conforme preceitua o inciso IX do art. $2^{\circ}$ da Lei . $^{\circ}$ 6.385/1976:

Art. $2^{\circ}$ São valores mobiliários sujeitos ao regime desta Lei:

[...]

IX - quando ofertados publicamente, quaisquer outros títulos ou contratos de investimento coletivo, que gerem direito de participação, de parceria ou de remuneração, inclusive resultante de prestação de serviços, cujos rendimentos advêm do esforço do empreendedor ou de terceiros (BRASIL, 1976).

Ainda nessa linha, vale demonstrar a definição atribuída pela própria Comissão de Valores Mobiliários, acerca do que seriam os chamados contratos de investimento coletivos:

O contrato de investimento coletivo pode ser entendido como o instrumento utilizado para captação de recursos dos investidores, para aplicação em determinado empreendimento, a ser implantando e gerenciado exclusivamente pelo empreendedor, com a promessa de distribuir entre os investidores os lucros do empreendimento (CVM, 2014, p 88).

Verifica-se, portanto, que o entendimento acerca da natureza jurídica dos contratos de investimentos coletivo, externado pelo próprio órgão regulador (CVM), encontra-se bem próximo à definição de crowdfunding, ou seja, uma operação de captação de recursos, mediante apelo ao público, para consecução de empreendimentos, com a possível distribuição dos lucros auferidos como resultado do empreendimento, tal como demonstrado acima.

Logo, seguindo uma visão estratégica do instituto, e no intuito de possibilitar a estruturação de um objetivo e/ou a resolução de um problema, desejo, necessidade e/ou vontade humana, com o menor custo possível, é bastante interessante a caracterização da operação de financiamento coletivo de projetos empresariais (novos ou já existentes) como contrato de investimento coletivo, pois é desnecessário, demorado e custoso procedimento de 
elaboração de normas específicas para essa operação, fazendo-se necessária tão somente a adequação das previsões já existentes, no intuito de respeitar algumas particularidades do crowdfunding, já demonstradas antes nessa pesquisa.

Interessante salientar, também, que, admitindo-se que a operação de financiamento coletivo de projetos empresariais coincide com o tipo legal do contrato de investimento coletivo, que é um valor mobiliário em decorrência de expressa disposição de lei, será possível a sua negociação tanto no mercado primário, quanto no mercado secundário de capitais, especialmente por meio do denominado mercado de balcão. E isso, sem dúvida, constitui incentivo à realização desse tipo de operação por agentes de mercado, ante a perspectiva de lucro com a sua negociação.

Frise-se, também, que considerar o crowdfunding como contrato de investimento coletivo acarreta a submissão dessa operação às regras de oferta pública de valores mobiliários já existentes, o que possibilita aos investidores experientes e atuantes no mercado de capitais, investir seguramente em negócios que se utilizem dessa estratégia jurídica de organização, o que pode acabar reduzindo os custos envolvidos. Ademais, como a remuneração da plataforma que intermedia a operação de crowdfunding já é garantida, nessa hipótese, haverá teoricamente incentivo para o aumento do número de agentes dispostos a realizar essa operação, o que irá propiciar aumento de investimento disponível àqueles que necessitam de capitalização para realizar os seus empreendimentos. A certeza do pagamento, por fim, poderá determinar maior liquidez do valor mobiliário, pois existirá a certeza de remuneração do agente que intermediar a operação, desde que atingido o valor estipulado pelo idealizador.

Todavia, as empresas startups, em sua maioria, são geralmente constituídos sob a forma de sociedade limitada, em razão da suposta aparente simplicidade e facilidade de organização e funcionamento desse tipo societário. Ocorre, entretanto, que, quando as empresas startups buscam investimentos para o desenvolvimento de seus objetivos e de suas atividades via emissão e negociação de valores mobiliários, a principal exigência que lhes é apresentada pela legislação consiste na obrigatoriedade de modificação do tipo societário para Sociedade Anônima (já que apenas excepcionalmente isso pode ser feito por intermédio de uma sociedade limitada, como acontece na regulação dos Fundos de Investimento em Participações - FIP, conforme artigo 5º, da Resolução CVM N. 578/2016 ${ }^{6}$ ), o que, teoricamente, permitiria maior transparência e controle pelos investidores.

${ }^{6}$ Art. $5^{\circ}$ O FIP, constituído sob a forma de condomínio fechado, é uma comunhão de recursos destinada à 
De fato, no caso das startups, dadas as incertezas do negócio e o caráter embrionário do mesmo, tal exigência se mostra teoricamente desmedida, pois, além disso, na operação de crowdfunding, como já salientado anteriormente, o idealizador apenas recebe o dinheiro investido se alcançar o montante estipulado como necessário e, para que ocorra o investimento, deverá oferecer todas as informações necessárias ao seu doador, o que facilita o controle do investidor relativamente às operações realizadas pelo idealizador, sem os custos inerentes à manutenção de uma sociedade anônima aberta.

Realmente, a natureza jurídica do investimento realizado por meio do crowdfunding nas empresas startups geralmente é de doação (pelo menos, no primeiro momento) e não de participação societária, pois o investidor-doador normalmente não tem interesse em vincular-se às incertezas e aos riscos do negócio nascente. E essa realidade, de fato, é um dificultador para simplesmente considerar o sistema de crowdfunding como um contrato de investimento coletivo, como um valor mobiliário.

Por isso, inclusive, os artigos 61-A a 61-D, da Lei Complementar n. 123/2006, com a redação estabelecida pela Lei Complementar n. 155, de 27 de outubro de 2016, passaram a prever o seguinte, especificamente em relação às sociedades enquadradas como microempresas ou empresas de pequeno porte, em virtude do faturamento anual:

\footnotetext{
Art. 61-A. Para incentivar as atividades de inovação e os investimentos produtivos, a sociedade enquadrada como microempresa ou empresa de pequeno porte, nos termos desta Lei Complementar, poderá admitir o aporte de capital, que não integrará o capital social da empresa.

$\S 1^{\circ}$ As finalidades de fomento a inovação e investimentos produtivos deverão constar do contrato de participação, com vigência não superior a sete anos.

$\S 2^{\circ} \mathrm{O}$ aporte de capital poderá ser realizado por pessoa física ou por pessoa jurídica, denominadas investidor-anjo.

$\$ 3^{\circ}$ A atividade constitutiva do objeto social é exercida unicamente por sócios regulares, em seu nome individual e sob sua exclusiva responsabilidade.

$\S 4^{\circ} \mathrm{O}$ investidor-anjo:

I - não será considerado sócio nem terá qualquer direito a gerência ou voto na administração da empresa;

II - não responderá por qualquer dívida da empresa, inclusive em recuperação judicial, não se aplicando a ele o art. 50 da Lei no 10.406, de 10 de janeiro de 2002 Código Civil;

III - será remunerado por seus aportes, nos termos do contrato de participação, pelo prazo máximo de cinco anos.
}

aquisição de ações, bônus de subscrição, debêntures simples, outros títulos e valores mobiliários conversíveis ou permutáveis em ações de emissão de companhias, abertas ou fechadas, bem como títulos e valores mobiliários representativos de participação em sociedades limitadas, que deve participar do processo decisório da sociedade investida, com efetiva influência na definição de sua política estratégica e na sua gestão. <http://www.cvm.gov.br/export/sites/cvm/legislacao/inst/anexos/500/inst578.pdf>. Acesso em 15 de maio de 2017. 
$\$ 5^{\circ}$ Para fins de enquadramento da sociedade como microempresa ou empresa de pequeno porte, os valores de capital aportado não são considerados receitas da sociedade.

$\S 6^{\circ}$ Ao final de cada período, o investidor-anjo fará jus à remuneração correspondente aos resultados distribuídos, conforme contrato de participação, não superior a $50 \%$ (cinquenta por cento) dos lucros da sociedade enquadrada como microempresa ou empresa de pequeno porte.

$\S 7^{\circ} \mathrm{O}$ investidor-anjo somente poderá exercer o direito de resgate depois de decorridos, no mínimo, dois anos do aporte de capital, ou prazo superior estabelecido no contrato de participação, e seus haveres serão pagos na forma do art. 1.031 da Lei $n^{\circ} 10.406$, de 10 de janeiro de 2002 - Código Civil, não podendo ultrapassar o valor investido devidamente corrigido.

$\S 8^{\circ} \mathrm{O}$ disposto no $\$ 7^{\circ}$ deste artigo não impede a transferência da titularidade do aporte para terceiros.

$\$ 9^{\circ}$ A transferência da titularidade do aporte para terceiro alheio à sociedade dependerá do consentimento dos sócios, salvo estipulação contratual expressa em contrário.

$\S 10$ O Ministério da Fazenda poderá regulamentar a tributação sobre retirada do capital investido.

Art. 61-B. A emissão e a titularidade de aportes especiais não impedem a fruição do Simples Nacional.

Art. 61-C. Caso os sócios decidam pela venda da empresa, o investidor-anjo terá direito de preferência na aquisição, bem como direito de venda conjunta da titularidade do aporte de capital, nos mesmos termos e condições que forem ofertados aos sócios regulares.

Art. 61-D. Os fundos de investimento poderão aportar capital como investidoresanjos em microempresas e empresas de pequeno porte (BRASIL, 2006).

Agora, então, as empresas startups classificadas como microempresas ou empresas de pequeno porte (que representam a grande maioria delas), na forma do disposto na Lei Complementar n. ${ }^{\circ}$ 123/2006, podem receber aportes de investidores via crowdfunding, por meio de contratos de investimento coletivo (valores mobiliários), independentemente de os investidores se tornarem sócios desde a data do investimento e de existirem outras regulações específicas expedidas pela CVM. Basta que as finalidades de fomento à inovação e investimentos produtivos constem do contrato de participação ou de investimento celebrado pelo chamado "investidor anjo", com vigência não superior a sete anos.

\section{CONCLUSÕES}

O Direito nasce no fato e, por isso, os fatos jurídicos devem ser considerados tanto no ensino, quanto na prática profissional, o que é mais evidente ainda no direito empresarial, dada a dinâmica e o dinamismo do mercado.

As empresas startups são geralmente sociedades voltadas para o desenvolvimento de novas tecnologias, de novos modelos de negócios, de novos produtos e/ou serviços, que atuam em mercados também novos e marcados pela incerteza decorrente da ausência de paradigmas. 
As atividades desenvolvidas pelas startups precisam ser financiadas por investidores que, em um primeiro momento, não têm interesse em ser sócios, dados os riscos envolvidos.

Todavia, a facilidade e o acesso a instrumentos de capitação de recursos são de extrema relevância para os sucessos de negócios iniciantes, com o modelo de negócios pautado na incerteza, como acontecem com as startups.

A Análise Estratégica do Direito possibilita ao seu aplicador, a construção de estratégias jurídicas que possam viabilizar a concreção dos objetivos dos sujeitos, com o menor custo possível, seja de tempo, recursos financeiros, de desgaste psicológico e/ou emocional.

Pensar o Direito de maneira estratégica, é necessidade que se impões nos dias atuais e isso é muito evidente no caso das startups, que precisam desenvolver estratégias jurídicas e financeiras para o desenvolvimento de suas atividades empresariais.

O crowdfunding pode ser visto como instrumento interessante e facilitador para capitação de recursos para as empresas startups, pois possibilita que o investimento seja direcionado àqueles empreendimentos que poderão atender, efetivamente, às necessidades, desejos e vontades dos consumidores.

A dinâmica diferenciada do crowdfunding garante que apenas os projetos viáveis e conectados com a realidade possam conseguir financiamento. E o financiamento é apresentado e solicitado aos investidores na medida exata das necessidades do negócio.

À primeira vista, por se tratar de capitação de recursos com o público investidor de forma indistinta, o financiamento coletivo por meio do sistema de crowdfunding deve ser considerado como um contrato de investimento coletivo, como um valor mobiliário, e se submeter à regulação do mercado de capitais e ao crivo da Comissão de Valores Mobiliários CVM.

Sendo a operação de crowdfunding então um contrato de investimento coletivo ele já encontra regulação na Lei n. 6.385/76 e na Instrução Normativa CVM n. 400/2003. Por isso, restou demonstrado nesta pesquisa ser desnecessária a elaboração de regulamentação específica sobre o tema, especialmente se forem consideradas as normas previstas na Lei Complementar n. 123/2006, a partir da redação estabelecida pela Lei Complementar n. 155/2016. De acordo com o disposto em todas essas normas jurídicas, o financiamento coletivo via crowdfunding pode continuar a ser realizado e incrementado, por meio dos contratos de investimento coletivos e sem a necessidade de o financiador ser sócio da startup. 
Tudo isso pode e dever ser considerado a partir do modelo mental proposto pela Análise Estratégica do Direito, para garantir a realização mais eficiente possível dos objetivos de financiamento e de crescimento sustentável das empresas startups.

\section{REFERÊNCIAS}

BRASIL. Lei 6.385, de 7 de dezembro de 1976. Dispõe sobre o mercado de valores mobiliários e cria a Comissão de Valores Mobiliários. Vade Mecum RT. 11.ed. rev., ampl. e atual. São Paulo: Revista dos Tribunais, 2015. Disponível, também, em: < http://www.planalto.gov.br/ccivil_03/leis/L6385.htm > . Acesso em: 17 maio 2017.

BRASIL. Lei Complementar 123, de 14 de dezembro de 2006. Institui o Estatuto Nacional da Microempresa e da Empresa de Pequeno Porte. Disponível em: < http://www.planalto.gov.br/ccivil_03/leis/LCP/Lcp123.htm >. Acesso em: 17 maio 2017.

BRASIL. Lei Complementar 155, de 27 de outubro de 2016. Altera a Lei Complementar no 123, de 14 de dezembro de 2006, para reorganizar e simplificar a metodologia de apuração do imposto devido por optantes pelo Simples Nacional. Disponível em: < http://www.planalto.gov.br/ccivil_03/leis/LCP/Lcp155.htm >. Acesso em: 17 maio 2017.

COCATE, Flávia Medeiros; PERNISA JÚNIOR, Carlos. Crowdfunding: estudo sobre o fenômeno virtual. Líbero, Revista do Programa de Pós-graduação da Faculdade Cásper Líbero, ano XV, jun. de 2012, n. ${ }^{\circ}$ 29. Disponível em: $<\mathrm{http}: / /$ seer.casperlibero.edu.br/index.php /libero/article/view/313/287>. Acesso em: $22 \mathrm{dez}$. 2016.

CVM. Edital de Audiência Pública n. ${ }^{\circ}$ 06/2016. <http://www.cvm.gov.br/audiencias_publicas/ap_sdm/2016/sdm0616.html>. Acesso em: 15 maio 2017.

- Instrução Normativa CVM n. ${ }^{\circ}$ 400, de 29 de dezembro de 2003. <http://www.cvm.gov.br/export/sites/cvm/legislacao/inst/anexos/400/inst400consolid.pdf>. Acesso em: 15 maio 2017.

- Instrução Normativa CVM n. ${ }^{\circ}$ 578, de 30 de agosto de 2016. <http://www.cvm.gov.br/export/sites/cvm/legislacao/inst/anexos/500/inst578.pdf>. Acesso em: 15 maio 2017.

O mercado de valores mobiliários brasileiro. 3.ed. Rio de Janeiro: Comissão de Valores Mobiliários, 2014. 376p.

GABRICH, Frederico de Andrade. Análise Estratégica do Direito. Belo Horizonte: Universidade Fumec - ${ }^{2}$ FCH, 2010. Disponível em: < 
http://www.clubedeautores.com.br/book/21796--

ANALISE_ESTRATEGICA_DO_DIREITO> .

PITTA, Andre Grünspun. A possibilidade de emissão de debêntures por sociedade limitada regida supletivamente pela lei das sociedades por ações. In: AZEVEDO, Luís André N. de Moura. CASTRO, Rodrigo R. Monteiro. Sociedade Limitada Contemporânea. São Paulo: Quartier Latin. 2013, p. 515/530).

RIES, Eric. A startup enxuta: como os empreendedores atuais utilizam a inovação contínua para empresas extremamente bem sucedidas. São Paulo: Lua de Papel, 2012.

VALIATI, Vanessa Amália Dalpizol. Crowdfunding e Indústria Cultural: as novas relações de produção e consumo baseadas na cultura da participação e no financiamento coletivo. Verso e Reverso, ano XXVII, n. ${ }^{\circ}$ 64, jan.-abr. 2013. Disponível em: $<$ http://revistas.unisinos.br/index.php/versoereverso/article/view/ver.2013.27.64.07/1400>. Acesso em: 22 dez. 2016.

VEIGA, Marcelo Godke. OIOLI, Erik Frederico. As Sociedades Limitadas e o Mercado de Capitais. In: AZEVEDO, Luís André N. de Moura. CASTRO, Rodrigo R. Monteiro. Sociedade Limitada Contemporânea. São Paulo: Quartier Latin. 2013, p. 627/663. 